\title{
DEVELOPMENT ASSESSMENT AND STRATEGY PLANNING IN CLOUD COMPUTING INDUSTRY
}

\author{
Wei-Hsiu Weng \\ National Chengchi University \\ No.64, Sec. 2, Zhinan Rd., Wenshan District, Taipei City 11605, \\ Taiwan \\ wh.weng@msa.hinet.net \\ Woo-Tsong Lin \\ National Chengchi University \\ No.64, Sec. 2, Zhinan Rd., Wenshan District, Taipei City 11605, \\ Taiwan \\ lin@mis.nccu.edu.tw
}

\begin{abstract}
This paper presents a study on the development assessment and strategy planning of Taiwan's cloud computing industry. The research is conducted through a nominal group technique, in-depth interviews and focus group discussions of industry professionals. The research process includes defining industry scope, assessing business environment, forecasting production value and outlining a strategy for the emerging cloud computing industry. Based on the analysis of cloud computing business prospects and possible strategies for the cloud computing industry, the result provides a reference for IT business developers and innovative vendors interested in entering the emerging cloud computing market.
\end{abstract}

Keywords: Cloud Computing, Industry Development, Nominal Group Technique, SWOT, Strategy

\section{INTRODUCTION}

The recent development of cloud computing has invoked tremendous attention from both IT vendors and organizational IT users. Many articles have discussed the technology aspects of cloud computing, however, research on the industrial development and business strategy aspects of cloud computing are still in the early stage. This research attempts to fill the gap between knowledge about technology and the business aspects of cloud computing. 
This paper provides an analysis of the business environment and possible layout of a business strategy that organizations may pursue in a cloud computing market. Starting from a classification of possible cloud computing business models, the scope of the cloud computing industry is defined. A development assessment of the industry is done by applying SWOT analysis and evaluating production value. Finally, a proposal is offered on possible business strategies for the industry to extend growth in this area.

\section{LITERATURE REVIEW}

The innovation of cloud computing has made a major impact on the products, services and business models of the IT software and hardware industries ${ }^{1,2,3}$. Cloud computing has therefore become an emerging concept and technology that has drawn the most attention from the IT software and hardware industries in the period of the recent global financial crisis. The sheer scope of the industry as well as the fact that it spans both the enterprise and consumer markets has led to much discussion on its future business potential ${ }^{4,5,6}$. Nevertheless, cloud computing technologies and business models as well as the new products, services, competition and alliances that arise as a result offer an emerging market that is well worth monitoring ${ }^{7}$.

Currently, vendors worldwide are exploiting possible business opportunity in the cloud computing market ${ }^{8,9}$. Factors that may influence adoption decisions of cloud computing, such as perception, attitude, and even organizational culture, have been investigated ${ }^{10,11}$. Garrison et al. ${ }^{12}$ investigated possible success factors for deploying cloud computing. Cloud computing also introduces new risk into information technology adoption. In Subashini and Kavitha ${ }^{13}$ present a survey of the different security risks which pose a threat to the cloud. In spite of the continuing research progress in cloud computing technology and adoption analysis, research on cloud computing regarding industry development and business strategy perspectives is still at its embryonic stage.

\section{RESEARCH METHOD}

Since many emerging technologies are still in the development phase, this study will employ qualitative methods instead of quantitative data analysis by way of nominal group technique (NGT), vendor interviews and focus groups. These methods are appropriate in this study because there are an insufficient number of well-established models for business strategy in the cloud computing industry. These methods aim at distilling and 
structuring opinions from the participants until a consensus or pattern is formed $^{14}$.

\subsection{Nominal Group Technique}

A nominal group technique is conducted to assist in the convergence process of data analysis ${ }^{15,16}$. For this objective, an expert panel of eleven persons were selected. The panel consisted of a CEO, CIO and a number of business managers from various domains of the Taiwanese IT industry. All were from publicly listed firms. The expert panel meetings were conducted over two time periods. The first meeting was held to discuss question 1 below. After that, vendor interviews and focus groups were conducted to gather data regarding industry status. Then a second expert panel meeting was held to discuss questions 2,3 and 4.

1. What is the scope of cloud computing industry?

2. With regards to this scope, what are the development environments in terms of internal competitiveness, as well as external impact of Taiwan's cloud computing industry?

3. With regards to these development environments, what is the development trend of Taiwan's cloud computing industry in terms of production value?

4. Recognizing internal and external development environments, what is a possible strategy that could be layout for Taiwan's cloud computing industry in order to extend the growing trend of production value?

\subsection{Vendor Interviews and Focus Groups}

Representative IT firms from Taiwan were selected according to industry scope as defined by the expert panel. The selection process was based on rankings of firm revenue, as well as their reputation in terms of technology innovation and market visibility. These firms are listed in the following table.

Table 1. Selected cases for vendor interviews and focus groups

\begin{tabular}{lc}
\hline \multicolumn{1}{c}{ Business Domain } & Number of Firms \\
\hline Independent Software Vendor (ISV) & 8 \\
System Integration Provider (SI) & 10 \\
Telecom Operator & 4 \\
Server and storage device manufacture & 6 \\
Networking device manufacture & 4 \\
Mobile device manufacture & 6 \\
\hline Total & 38 \\
\hline
\end{tabular}


The data items collected from vendor interviews were as follows:

1. Forecast revenue of a firm that is related to cloud computing business.

2. Vision, strategy, products or service related to cloud computing market.

3. Important trends observed regarding cloud computing market.

After individual vendor interviews, vendors were divided into four focus groups to discuss the following issuesk ${ }^{17}$.

1. The major strengths and weaknesses and the possible opportunities and threats for the Taiwanese cloud computing industry.

2. Optimistic and pessimistic estimation criteria of Taiwanese cloud computing production value.

3. Proposal of business strategies for industry development.

Table 2. Scope of the cloud computing industry

\begin{tabular}{|c|c|c|}
\hline $\begin{array}{l}\text { Cloud Computing } \\
\text { Product and } \\
\text { Service }\end{array}$ & Main Value Activities & $\begin{array}{l}\text { Business Models } \\
\text { And Paradigms }\end{array}$ \\
\hline Cloud user device & $\begin{array}{l}\text { Entry into the cloud supply chain } \\
\text { through smartphones, tablets, } \\
\text { netbooks, and other products. }\end{array}$ & Apple, Google \\
\hline $\begin{array}{l}\text { Cloud } \\
\text { infrastructure } \\
\text { equipment }\end{array}$ & $\begin{array}{l}\text { Entry into the cloud supply chain } \\
\text { through servers, storage } \\
\text { equipment, network } \\
\text { communication equipment, power } \\
\text { suppliers, and other branded } \\
\text { products or OEM operations. }\end{array}$ & $\begin{array}{l}\text { Cisco, EMC, IBM, } \\
\text { HP, Oracle }\end{array}$ \\
\hline $\begin{array}{l}\text { Cloud service and } \\
\text { data center } \\
\text { operation }\end{array}$ & $\begin{array}{l}\text { Provision of broadband service, } \\
\text { data center services, and various } \\
\text { XaaS (SaaS, PaaS, IaaS) services } \\
\text { needed in cloud computing. }\end{array}$ & $\begin{array}{l}\text { Amazon, Google, } \\
\text { Facebook, } \\
\text { Salesforce.com }\end{array}$ \\
\hline $\begin{array}{l}\text { Cloud } \\
\text { infrastructure } \\
\text { software and IT } \\
\text { service }\end{array}$ & $\begin{array}{l}\text { Assistance offered to cloud service } \\
\text { and infrastructure setup through } \\
\text { system integration, software } \\
\text { development, consultancy } \\
\text { services, and other operations. }\end{array}$ & $\begin{array}{l}\text { IBM, Microsoft, } \\
\text { Symantec, VMWare }\end{array}$ \\
\hline
\end{tabular}




\section{RESULTS}

\subsection{Scope of the Cloud Computing Industry}

By looking into the definition ${ }^{18}$ and the business models ${ }^{4,19,20,21}$ ) of cloud computing, and analyzing value activities $22,23,24$ of IT vendors, the scope of the cloud computing industry was discussed by the expert panel. The results of the discussion are exhibited in Table 2.

\subsection{Development Assessment of Taiwan's Cloud Computing Industry}

In the vendor interviews and focus group sessions, the possible strengths, weaknesses, opportunity and threat attributes of Taiwan's cloud computing industry were collected. These items were compiled and submitted to the expert panel as references for SWOT analysis ${ }^{25,26,27}$. The expert panel examined these proposed items, and performed a series of screening, prioritizing and consolidating activities. The final result of the SWOT analysis is exhibited in Table 3.

Table 3. SWOT analysis of Taiwan's cloud computing industry

\begin{tabular}{|l|}
\hline Strengths \\
\hline S1. Possesses both hardware and \\
software solutions and provides \\
professional consultancy services \\
experience.
\end{tabular}

S2. Cooperates with the global leading companies for many years, and prices are flexible.

S3. Possesses in-depth vertical domain knowledge and localized know-how as well.

O1. Open up the market of private cloud deployment.

O2. Develop the SaaS version of software to attract new customers.

O3. Deliver cloud services governance, including security, auditing, and quality control.

O4. Provide enterprise mobile cloud application software and services.
Weaknesses

W1. Customers are mostly large enterprises or government agencies; fewer dealings with SMEs and consumers.

W2. Weak research and development of key software technologies such as virtualization and big data analytics.

T1. Global leading companies lead technologies and standards.

T2. Part of the business is replaced by emerging cloud services from other countries.

T3. Industries rise in emerging markets such as in mainland China, India, and others. 


\subsection{Forecast of Taiwan's Cloud Computing Production Value}

The production value represents the total revenue of the industry and is a key performance index for industry development. By evaluating the forecast revenue of Taiwan's vendors in the industry scope, and considering the business environment in the mean time, the expert panel estimated the growth rates of production value from 2014 to 2018, and concluded that Taiwan's cloud computing production value is expected to achieve steady growth through 2018, as shown in Table 4.

Table 4. Production value of Taiwan's cloud computing industry

\begin{tabular}{ccccccc}
\hline Year & 2013 & 2014 & 2015 & 2016 & 2017 & 2018 \\
\hline Production Value & 14,471 & 16,983 & 19,689 & 22,112 & 24,733 & 27,526 \\
$\begin{array}{c}\text { (USD Million) } \\
\text { Growth Rate (\%) }\end{array}$ & - & $17.36 \%$ & $15.93 \%$ & $12.31 \%$ & $11.85 \%$ & $11.29 \%$ \\
\hline
\end{tabular}

Table 5. Strategy planning for Taiwan's cloud computing industry

\begin{tabular}{|c|c|}
\hline Strength/Opportunity Strategy & Weakness/Opportunity Strategy \\
\hline $\begin{array}{l}\text { SO1. Develop private cloud } \\
\text { deployment and value-added } \\
\text { services }\end{array}$ & $\begin{array}{l}\text { WO1. Develop the On Demand } \\
\text { version of the application } \\
\text { software for developing SME }\end{array}$ \\
\hline SO2. Strengthen enterprise mobile & market \\
\hline $\begin{array}{l}\text { application development and } \\
\text { deployment }\end{array}$ & $\begin{array}{l}\text { WO2. Cooperate with the ISVs in } \\
\text { promoting the SaaS business }\end{array}$ \\
\hline $\begin{array}{l}\text { SO3. Extend cloud services } \\
\text { governance related business }\end{array}$ & $\begin{array}{l}\text { WO3. Develop consumers' personal } \\
\text { cloud storage and collaboration } \\
\text { services }\end{array}$ \\
\hline Strength/Threat Strategy & Weakness/Threat Strategy \\
\hline
\end{tabular}

ST1. Strategically ally with mainland WT1. Cooperate with leading foreign China, India, and other industries to develop emerging markets

ST2. Develop cheap mobile devices to leverage the Cloud Service leading companies' existing customer group companies in promoting the emerging business of Big Data analytics

WT2. Combine proposed solutions with the issues of carbon reduction, remote back-up, and disaster recovery 


\subsection{Strategy Planning for Taiwan's Cloud Computing Industry}

Following the method for establishing a TOWS strategy matrix from the SWOT analysis introduced by Weihrich ${ }^{18}$, strategies were planned by the expert panel for Taiwan's cloud computing industry to extend the growing trend of production value. The result is summarized in Table 5.

\section{CONCLUSIONS}

\subsection{Research Contributions}

The cloud computing industry in accordance with related value activities are divided into four sub-industries, namely, the cloud infrastructure software and IT service industries, the cloud service and data center operation industry, the cloud infrastructure equipment industry, and finally the cloud user device industry. The internal strengths and weaknesses, the external opportunities and threats, as well as the production value forecast were analyzed and presented. These findings were then taken as the base artifacts for strategy planning.

Vendors interested in exploring the market opportunities of cloud computing can use this analysis process and outcome of this research as a reference for their strategic planning, and avoid many unnecessary trial-and-error efforts. In particular, with a clear picture of the cloud computing value activities and business environments, vendors can position themselves more precisely for a market sector to their competitive advantage.

\subsection{Future Research Suggestions}

More studies on cloud computing business models and strategies can be conducted further by combining strategy planning with adoption considerations. In particular, the following issues are worthy of attention.

1. Cloud computing business strategy planning in various vertical industry sectors ${ }^{28}$.

2. Cloud computing business strategy planning for various sizes of enterprise $^{29}$.

3. Cloud computing business strategy planning for various levels of IT maturity and IT spending of enterprises ${ }^{12,30}$. In addition, more decision factors that affect the enterprise adoption of cloud computing could be examined and more insights could be obtained by incorporating these decision factors into the analysis process of this research. 


\section{REFERENCES}

[1] K. Keahey, and T. Freeman, Science clouds: Early experiences in cloud computing for scientific applications. Workshop on Cloud Computing and Its Applications (CCA08). Chicago, USA: Illinois, 2008.

[2] M. Armbrust, A. Fox, R. Griffith, A. Joseph, R. Katz, A. Konwinski, G. Lee, D. Patterson, A. Rabkin, I. Stoica, and M. Zaharia, A view of Cloud computing. Communication of the ACM, 53(4), p50-58, 2010. http://dx.doi.org/10.1145/1721654.1721672.

[3] R. Buyya, S. Venugopal, and C.S. Yeo, Market oriented cloud computing: Vision, hype and reality for delivering IT services as computing utilities. In K. Li, W. Zhou, and M. Valero (Eds.), Proceedings of the 10th IEEE International Conference on High Performance Computing and Communications (p5-13). Dalian: IEEE Press, 2008. http://dx.doi.org/10.1109/HPCC.2008.172.

[4] B. Iyer, and J.C. Henderson, Preparing for the future: Understanding the seven capabilities of cloud computing. MIS Quarterly Executive, 9(2), p117-131, 2010.

[5] H. Katzan Jr., Cloud software service: Concepts, technology, economics. Service Science, 1(4), p256-269, 2009. http://dx.doi.org/10.1287/serv.1.4.256.

[6] I. Foster, Y. Zhao, I. Raicu, and S. Lu, Cloud computing and grid computing 360-degree compared. In F. Cappello, Z. Huang, and O. Rana (Eds.), Proceedings of the IEEE Grid Computing Environments Workshop (p1-10). Austin, TX: IEEE Press, 2008. http://dx.doi.org/10.1109/GCE.2008.4738445.

[7] P. Helland, Condos and clouds. Communication of the ACM, 56(1), p50-59, 2013. http://dx.doi.org/10.1145/2398356.2398374.

[8] B. Sotomayor, R.S. Montero, I.M. Llorente, and I. Foster, Capacity leasing in cloud systems using the OpenNebula engine. Workshop on Cloud Computing and its Applications (CCA08). Illinois: Chicago, USA, 2008.

[9] M.A. Vouk, Cloud computing-issues, research and implementations. Journal of Computing and Information Technology, 16(4), p235-246, 2008. http://dx.doi.org/10.2498/cit.1001391.

[10] A. Lin, and N.-C. Chen, Cloud computing as an innovation: Perception, attitude, and adoption. International Journal of Information Management, $\quad$ 32, p533-540, 2012. http://dx.doi.org/10.1016/j.ijinfomgt.2012.04.001.

[11] N. Sultan, and S. van de Bunt-Kokhuis, Organisational culture and cloud computing: Coping with a disruptive innovation. Technology Analysis \& Strategic Management, 24(2), p167-179, 2012. http://dx.doi.org/10.1080/09537325.2012.647644. 
[12] G. Garrison, S. Kim, and R.L. Wakefield, Success factors for deploying cloud computing. Communications of the ACM, 55(9), p62-68, 2012. http://dx.doi.org/10.1145/2330667.2330685.

[13] S. Subashini, and V. Kavitha, A survey on security issues in service delivery models of cloud computing. Journal of Network and Computer Applications, 34(1), p1-11, 2011. http://dx.doi.org/10.1016/j.jnca.2010.07.006.

[14] A. Smaling, Inductive, analogical, and communicative generalization. International Journal of Qualitative Methods, 2(1), p1-31, 2003.

[15] C. Boddy, The nominal group technique: An aid to brainstorming ideas in research. Qualitative Market Research, 15(1), p6-18, 2012. http://dx.doi.org/10.1108/13522751211191964.

[16] S. Lloyd, Applying the nominal group technique to specify the domain of a construct. Qualitative Market Research, 14(1), p105-121, 2011. http://dx.doi.org/10.1108/13522751111099346.

[17] L. Vicsek, A scheme for analyzing the results of focus groups. International Journal of Qualitative Methods, 6(4), p22-34, 2007.

[18] P. Mell, and T. Grance, The NIST definition of cloud computing. Special

Publication (http://csrc.nist.gov/publications/nistpubs/800-145/SP800-145.pdf), 800(145), p1-3, 2011.

[19] A. Afuah, and C.L. Tucci, Internet business models and strategies: Text and cases. Boston: McGraw-Hill , 2001.

[20] M. Morris, M. Schindehutte, and J. Allen, The entrepreneur's business model: Toward a unified perspective. Journal of Business Research, 58(6), p726-735, 2005. http://dx.doi.org/10.1016/j.jbusres.2003.11.001.

[21] M.A. Rappa, The utility business model and the future of computing services. IBM Systems Journal, 43(1), p32-42, 2004. http://dx.doi.org/10.1147/sj.431.0032.

[22] M.E. Porter, Competitive Strategy. New York: Free Press, 1980.

[23] M.E. Porter, Competitive Advantage. New York: Free Press, 1985.

[24] M.E. Porter, Towards dynamic theory of strategy. Strategic Management Journal, 12(S2), p95-117, 1991. http://dx.doi.org/10.1002/smj.4250121008.

[25] D.W. Pickton, and S. Wright, What's SWOT in strategic analysis? Strategic Change, 7(2), p101-109, 1998. http://dx.doi.org/10.1002/(SICI)1099-1697(199803/04)7:2\%3C101::AI D-JSC332\%3E3.0.CO;2-6.

[26] H. Weihrich, The TOWS matrix: A tool for situational analysis. Long Range Planning, 15(2), p54-66, 1982. http://dx.doi.org/10.1016/0024-6301(82)90120-0.

[27] R.G. Dyson, Strategic development and SWOT analysis at the 
University of Warwick. European Journal of Operational Research 152(3), p631-640, 2004. http://dx.doi.org/10.1016/S0377-2217(03)00062-6.

[28] S. Basu, A.H. Karp, J. Li, J. Pruyne, J. Rolia, S. Singhal, J. Suermondt, and R. Swaminathan, Fusion: Managing healthcare records at cloud scale. IEEE Computer, 45(11), p42-49, 2012. http://dx.doi.org/10.1109/MC.2012.291.

[29] P. Gupta, A. Seetharaman, and J.R. Raj, The usage and adoption of cloud computing by small and medium businesses. International Journal of Information Management, 33(5), p861- 874, 2013. http://dx.doi.org/10.1016/j.ijinfomgt.2013.07.001.

[30] L. Jain, and S. Bhardwaj, Enterprise cloud computing:Kkey considerations for adoption. International Journal of Engineering and Information Technology, 2(2), p113-117, 2010. 